\title{
Increased Curvature of the Tentorium Cerebelli in Idiopathic Intracranial Hypertension
}

\author{
(DP.P. Morris, (D) N. Lachman, (DD.F. Black, (D)R.A. Carter, (D). Port, and (D) N. Campeau
}

\begin{abstract}
BACKGROUND AND PURPOSE: Transverse sinus effacement is detectable on MRV examinations in almost all patients with idiopathic intracranial hypertension. This effacement of the transverse sinus is presumed to be mediated by elevation of intracranial pressure, resulting in compression and inward collapse of the dural margins of the sinus. We sought to establish whether supratentorial broad-based downward deformity of the tentorium might explain transverse sinus effacement in idiopathic intracranial hypertension.
\end{abstract}

MATERIALS AND METHODS: MRV examinations of 53 adult patients with idiopathic intracranial hypertension were reviewed retrospectively and compared with 58 contemporaneously acquired controls. The curvature of the tentorium with reference to a line connecting the transverse sinus laterally with the confluence of the tentorial leaves medially was calculated as a segment of a circle. The height and area of the segment and the angle subtended by the midpoint of the tentorium from the falx were calculated.

RESULTS: The height and area of the segment described by the chord connecting the transverse sinus with the apex of the tentorial confluence and subtended midtentorial angle were greater in the idiopathic intracranial hypertension group; this finding supports the hypothesis that increased tentorial bowing is present in idiopathic intracranial hypertension.

CONCLUSIONS: Increased bowing of the tentorium in patients with idiopathic intracranial hypertension compared with controls is a new observation, lending itself to new hypotheses on the nature and localization of elevated intracranial pressure in idiopathic intracranial hypertension. Bowing of the tentorium may play a part in distorting the contour of the transverse sinuses, resulting, at least in part, in the effacement of the transverse sinuses in idiopathic intracranial hypertension.

ABBREVIATIONS: ICP = intracranial pressure; $I \mathrm{IH}=$ idiopathic intracranial hypertension

I diopathic intracranial hypertension (IIH), alternatively known as pseudotumor cerebri, is a poorly understood condition characterized by elevation of intracranial pressure (ICP) in the absence of a definable intracranial mass or other anatomic explanation. ${ }^{1,2}$ The diagnosis is established by the Modified Dandy criteria, revised in 2013 to incorporate imaging findings, but the essence of the diagnosis is an opening CSF pressure of $>250 \mathrm{~mm}$ $\mathrm{H}_{2} \mathrm{O}$ in adults or $280 \mathrm{~mm} \mathrm{H}_{2} \mathrm{O}$ in children without obvious cause. $^{3,4}$ The diagnosis can be elusive on clinical grounds due to the nonspecific and fluctuating nature of the clinical symptoms. Neuroradiologic diagnosis of IIH can also be difficult on MR imaging because it relies on inconsistently present anatomic corre-

Received September 13, 2016; accepted after revision May 6, 2017.

From the Departments of Radiology (P.P.M., D.F.B., R.A.C., J.P., N.C.) and Anatomy (N.L.), Mayo Clinic, Rochester, Minnesota.

Please address correspondence to Pearse Morris, MB, BCh, Department of Radiology, Mayo Clinic, 200 First St SW, Rochester, MN 55905; e-mail: morris.ppearse@mayo.edu

http://dx.doi.org/10.3174/ajnr.A5289 lates of chronically elevated ICP, such as flattening of the diaphragm sellae, distension of the optic nerves sheaths, flattening of the posterior sclera, or signs of papilledema. ${ }^{5,6}$ Remodelling of the pituitary gland contour or of the sella turcica itself may be seen in $40 \%-60 \%$ of patients, and ocular findings, though reportedly present in $88 \%$ of pediatric patients under anesthesia, are less consistently perceived in adult patients. ${ }^{7}$ Vascular studies, specifically gadolinium-bolused MR venography, have shown that $94 \%$ of adult patients with IIH demonstrate a very characteristic appearance of bilateral effacement/attenuation of the contours of the transverse sinuses, so-called "transverse sinus stenosis." 8-10 This finding has been the subject of potential therapeutic focus in some patients with IIH refractory to medical therapy alone, with clinical improvement or stabilization reported in most severely ill patients treated with transvenous stent placement. It is a curious observation that this dural sinus effacement is consistently and exclusively confined to the lateral margins of the transverse sinuses where the upward sweep of the sinus is maximal on a sagittal view and the scope of the suspension curve or "hammock-sling" of the tentorial cerebelli is maximal on a coronal view. 


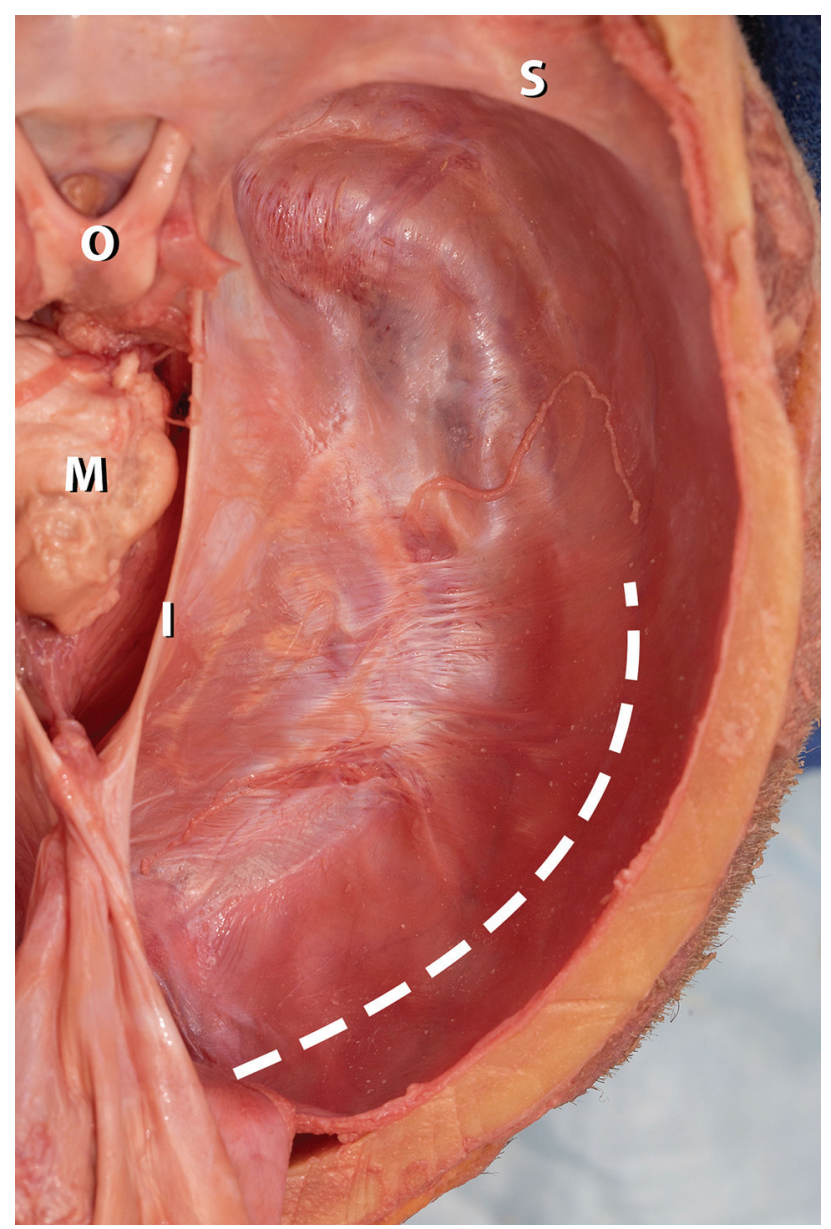

FIG 1. Image from an anatomic dissection of a human cadaver viewed from above and behind. The cerebral hemispheres and diencephalon have been removed, exposing the tentorial margin and cut surface of the midbrain (M). The lesser wing of the sphenoid (S) and optic chiasm (O) lie on the upper aspect of the image. The falx cerebri is folded posteriorly in the midline, causing retraction of the tentorial incisura (I). The approximate course of the hidden transverse sinus is represented by the broken line. The point of the image is to emphasize the smooth, featureless sweep of the tentorium as it splits around the margins of the transverse sinus and continues laterally as the dural margin of the right hemicranium. The transition is so featureless that the margins of the transverse sinus cannot be either visualized or easily palpated in this example, raising the question of how even mildly elevated intracranial pressure could cause a focal indentation on this featureless span of "tough" tissue to bring about effacement of the buried transverse sinus.

During anatomic brain dissection, the sweep of the tentorium cerebelli blends so seamlessly with the margins of the transverse sinus (Fig 1) that it becomes difficult to envision how moderately elevated ICP could efface the transverse sinus in such a focal manner. This force would have to exert a focal indentation on the margins of the transverse sinus and create a definable furrow along the sinus, thus requiring a marked degree of local dural stretching. It is more cogent to invoke the Laplace Law pertaining to tension along a curved surface and to suggest that supratentorial pressure would be more likely to exert a generalized effect on the broad expanse of the tentorium. If such an effect were present, it should be most robustly detectable where the sweep of the tentorium is at its widest, which, coincidentally or otherwise, also corresponds with the characteristic location of the effacement of

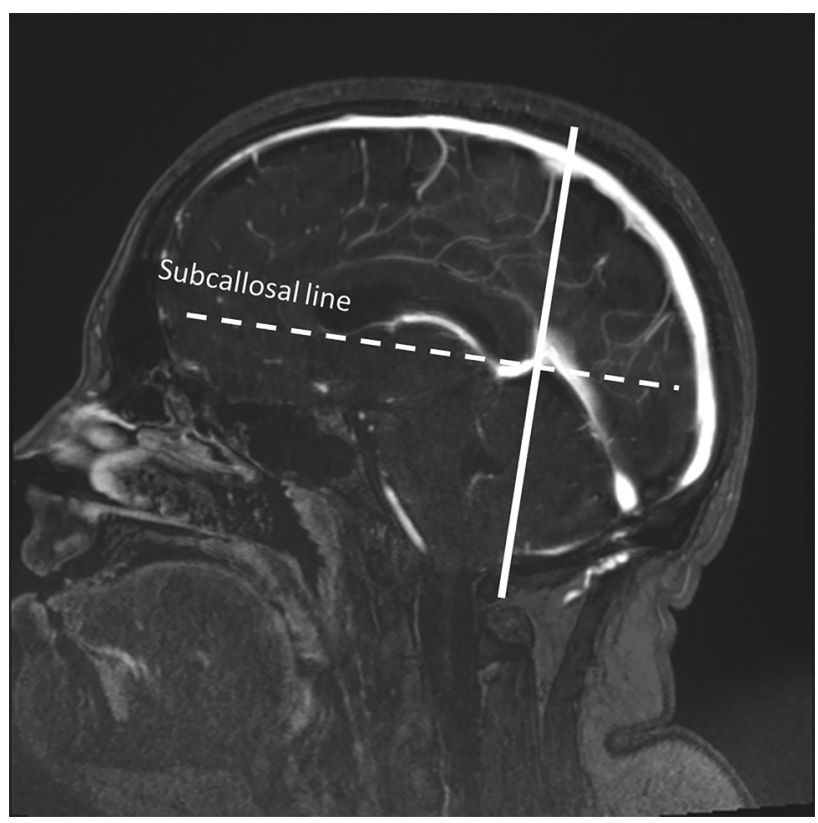

FIG 2. A midline sagittal view from the source image data was used for orientation of the oblique coronal plane and then for measurements. The oblique coronal plane (continuous line) intersects the junction of the great vein of Galen and the straight sinus and runs in a plane orthogonal to the subcallosal line (dotted line).

the transverse sinus seen in IIH. To advance this hypothesis, that the effacement of the transverse sinus in IIH may be, in some part, secondary to diffusely distributed ICP effects on the tentorium rather than a focal effect on the margins of the transverse sinus, we sought to determine whether a greater degree of curvature of the tentorium could be detected in patients with IIH compared with a control group.

\section{MATERIALS AND METHODS}

A retrospective review of MR images and clinical records with institutional review board approval was conducted on 53 patients with IIH and 58 adult controls. Subjects were identified through a key word search of the electronic medical records spanning a 5-year period, 2010-2015. Patients with IIH ( $n=$ 53 ; $16-60$ years of age) were diagnosed by meeting the Modified Dandy diagnostic criteria in the absence of other identifiable explanations for their symptoms or elevated ICP. Control subjects ( $n=58 ; 16-60$ years of age) were all diagnosed with migraine-type headache or other nonspecific headaches and were gathered sequentially in chronologic order from a list of non-IIH subjects with MR imaging and MRV during the same period. Controls did not demonstrate identifiable intracranial pathology, elevation of ICP, dural sinus thrombosis, or other anatomic causes for headache.

\section{Image Review}

Source images from 3D gadolinium-bolused MRV examinations were used for analysis. Data files were imported into an independent Advantage Windows Workstation (GE Healthcare, Milwaukee, Wisconsin) and reformatted in multiplanar reconstructions at a resolution of $0.6 \mathrm{~mm}$ per pixel. 

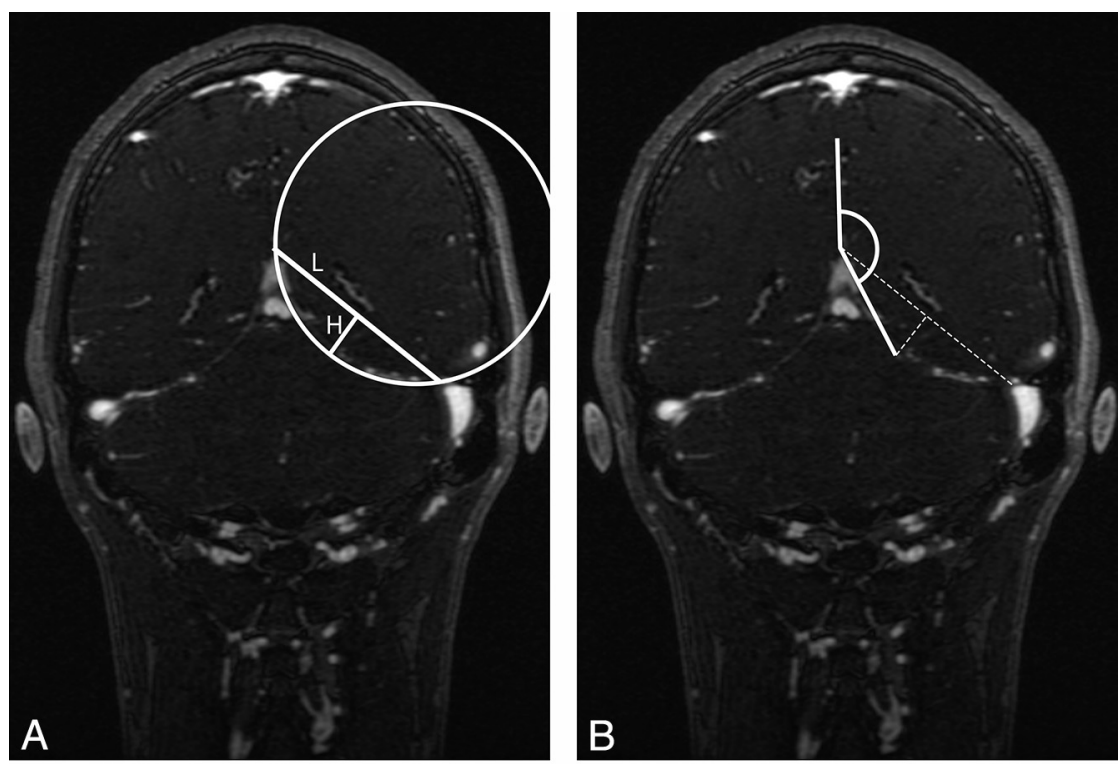

sagittal view passes at or near the widest transverse diameter of the cerebellar tentorium and was used to define the measurement landmarks of the tentorium (Fig 2). The curvature of the tentorium was determined from the theoretic chord segment length and height of an imperfect circle inscribing the curvature of the tentorium (Fig 3A). Specifically, the chord length of the circle segment passing between the midline apposition points of the tentorial leaves above the venous confluence and the lateral point where the tentorium splits to enfold the transverse sinus was measured with workstation tools. The height of the segment was measured orthogonal to and at the midpoint of segment length. With the segment of a circle defined by segment length and height, it is
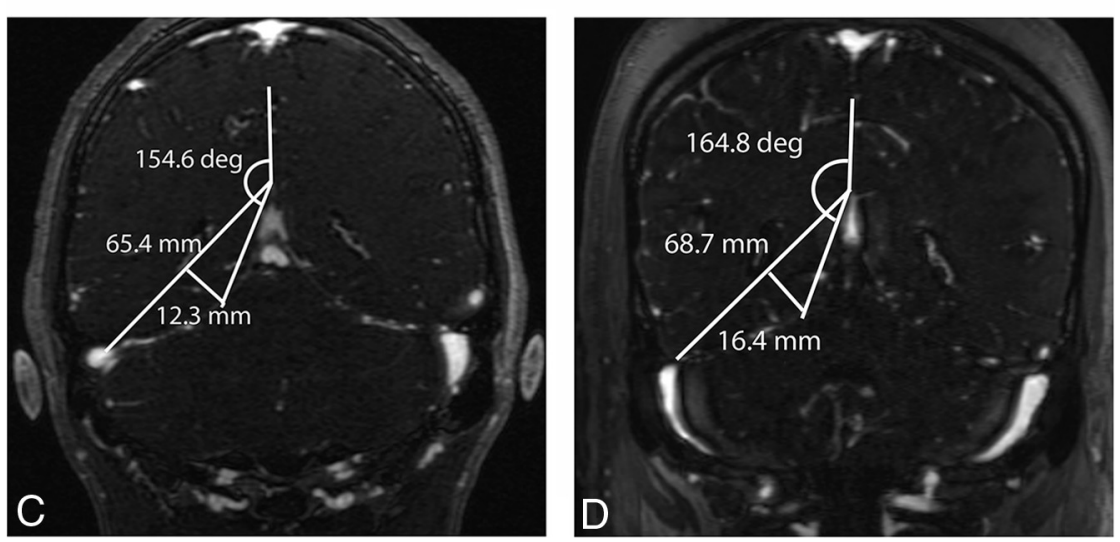

FIG 3. Illustration of the geometric landmarks used to calculate the curvature of the tentorium. $A$, A segment of a theoretic circle of chord length $(L)$ and height $(H)$ is constructed by using landmarks for the insertion points of the tentorium cerebelli, as described in the text. The conformity of the circle perimeter to the actual sweep of the tentorial curve may be imperfect, but this is of no consequence because its role is primarily illustrative, to help envision the geometric relationship of the primary anatomic points. $B$, With the same anatomic points illustrated in $A$, an angle subtended by the midpoint of the tentorium is calculated with the midline tentorial convergence as an apex and the vertical falx cerebri as a baseline. $C$, Illustration of these measurements in a control subject, a 22-year-old male patient with an ultimate diagnosis of migraine headaches. $D$, Illustration of same measurements in a patient with $\mathrm{IIH}$, a 22-year-old female patient with a body mass index of 48.2 and an opening CSF pressure of $338 \mathrm{~mm} \mathrm{H}_{2} \mathrm{O}$.

Table 1: Characteristics of patients with idiopathic intracranial hypertension and controls

\begin{tabular}{lccc}
\hline \multicolumn{1}{c}{ Variable } & Controls $(\boldsymbol{n}=\mathbf{5 8})$ & $\mathrm{IIH}(\boldsymbol{n}=\mathbf{5 3})$ & $\boldsymbol{P}$ \\
\hline Age (mean) $(\mathrm{yr})$ & $34.8 \pm 9.7$ & $31.3 \pm 10.3$ & .06 \\
Sex (male/female) & $44: 14$ & $50: 3$ & .008 \\
$\mathrm{BMI}\left(\right.$ mean) $\left(\mathrm{kg} / \mathrm{m}^{2}\right)$ & $28.1 \pm 7.6$ & $36.9 \pm 8.9$ & $<.0001$ \\
Weight (mean) $(\mathrm{Kg})$ & $80.4 \pm 28.4$ & $101.7 \pm 28.7$ & .0002 \\
$\begin{array}{c}\text { Opening CSF pressure } \\
\text { (mean) }\left(\mathrm{mm} \mathrm{H} \mathrm{H}_{2} \mathrm{O}\right)\end{array}$ & $\mathrm{NA}$ & $363.2 \pm 84$ & $\mathrm{NA}$ \\
\hline
\end{tabular}

Note:-BMI indicates body mass index; NA, not applicable.

\section{Measurements}

Tentorial Radius of Curvature. The apex of the tentorial convergence in the midline was selected by finding the midline sagittal image showing the confluence of the great vein of Galen and the straight sinus. An oblique coronal plane passing through this point and lying orthogonal to the subcallosal line ${ }^{11}$ on the midline

thus possible to calculate the radius of curvature of this theoretic circle and the area of the segment. These measurements were performed bilaterally.

Falx-to-Midtentorium Angle. To circumvent potential bias in defining the lateral point of the chord segment length, we devised a second index of tentorial curvature (Fig 3B). With the same oblique coronal image defined above, the angle defined with the vertex at the midline confluence of the tentorial leaves and rays subtending the midpoint of the tentorial curve and the midline falx cerebri was measured bilaterally in all cases. An increase in this angle was expected to indicate a greater degree of bowing of the tentorium in the patients with IIH group, independent of the measurement technique described in "Tentorial Radius of Curvature" above (Fig 3C, -D).

\section{Statistics}

Summarized data are presented as mean ( \pm SD) or frequency (percentage). Two-sample $t$ tests and Fisher exact tests were used for differences in demographic and imaging findings between controls and subjects with IIH. Multiple linear regression was used to adjust for the effects of age, body mass index, and sex. Two-sided $P$ values $<.05$ were considered statistically significant. Statistical analysis was conducted with JMP Pro 11.2 for Mac (SAS Institute, Cary, North Carolina).

\section{RESULTS}

Group comparisons are presented in Table 1. A greater representation of male subjects was present in the control group compared with patients with $\mathrm{IIH}$, but mean ages were comparable. Body 
Table 2: Measurement of the tentorial curvature

\begin{tabular}{lccccc}
\hline & $\begin{array}{c}\text { Height Right } \\
(\text { Mean) }(\mathbf{m m})\end{array}$ & $\begin{array}{c}\text { Height Left } \\
(\text { Mean) }(\mathbf{m m})\end{array}$ & $\begin{array}{c}\text { Area of Segment } \\
\text { Right (Mean) }\left(\mathbf{m m}^{2}\right)\end{array}$ & $\begin{array}{c}\text { Area of Segment } \\
\left.\text { Left (Mean) }(\mathbf{m m})^{2}\right)\end{array}$ & $\begin{array}{c}\text { Falx-Tentorium } \\
\text { Angle }(\mathbf{M e a n})(\mathbf{m m})\end{array}$ \\
\hline Controls $(n=58)$ & $11.6 \pm 1.7$ & $11.5 \pm 1.8$ & $515.6 \pm 104.2$ & $515.6 \pm 113.3$ & $151.5 \pm 4.4$ \\
$\mathrm{IIH}(n=53)$ & $14.6 \pm 2.2$ & $14.2 \pm 2.1$ & $676.1 \pm 130.5$ & $688.2 \pm 131.4$ & $154.1 \pm 3.4$ \\
$R^{2}$ & .31 & .33 & .32 & .33 & .091 \\
$P^{\mathrm{a}}$ & $<.0001$ & $<.0001$ & $<.0001$ & $<.00001$ & $<.0007$ \\
\hline
\end{tabular}

a values are significant.

Table 3: Regression analysis controlling for the effect of BMI, age, and sex

\begin{tabular}{|c|c|c|c|c|c|c|}
\hline & $\begin{array}{c}\text { Controls (Mean) } \\
(n=58)\end{array}$ & $\begin{array}{c}\text { IIH (Mean) } \\
(n=53)\end{array}$ & $\begin{array}{l}\text { Unadjusted } \\
\text { Difference }\end{array}$ & $P$ & $\begin{array}{l}\text { Adjusted } \\
\text { Difference }\end{array}$ & $\begin{array}{c}\text { Adjusted } \\
P \text { Value }\end{array}$ \\
\hline Height right (mm) & $11.6 \pm 1.7$ & $14.5 \pm 2.2$ & 2.64 & $<.0001$ & 2.21 & $<.0001$ \\
\hline Height left (mm) & $11.5 \pm 1.7$ & $14.2 \pm .1$ & 2.69 & $<.0001$ & 2.60 & $<.0001$ \\
\hline Area of segment right $\left(\mathrm{mm}^{2}\right)$ & $515.6 \pm 104.2$ & $676.1 \pm 130.5$ & 160.48 & $<.0001$ & 133.92 & $<.0001$ \\
\hline Area of segment left $\left(\mathrm{mm}^{2}\right)$ & $515.6 \pm 113.3$ & $688.2 \pm 131.4$ & 172.24 & $<.0001$ & 161.98 & $<.0001$ \\
\hline Falx-tentorium angle & $151.5 \pm 4.4$ & $154.1 \pm 3.4$ & 2.62 & $<.0007$ & 2.22 & $<.023$ \\
\hline
\end{tabular}

mass index levels were significantly higher in the IIH group as expected.

All parameters of tentorial curvature, height of the segment, area of the segment, and the angle subtended by the midpoint of the tentorium showed a consistent indication of greater bowing in the IIH group compared with controls (Table 2). The distance from the baseline defined by the medial and lateral tentorial insertion points to the tentorial curvature itself was significantly greater in the IIH group. The angle subtended by the tentorial midpoint and the falx cerebri was also demonstrably greater, indicating a deeper degree of curvature compared with controls. With multiple linear regression analysis, this effect persisted after adjustment for sex, age, and body mass index (Table 3 ).

\section{DISCUSSION}

Our observations appear to be in agreement with our initial hypothesis that a downward deflection of the tentorium cerebelli is detectable in patients with IIH. This leads us to the hypothesis that this deflection could explain, in part or in whole, the distortion or effacement of the transverse sinuses seen in IIH.

From a mechanical point of view, this hypothesis is reasonable in that a diffuse supratentorial mass effect, likely mediated through a broad-based change in brain volume in patients with $\mathrm{IIH}$, would be more likely to exert a deflection on the entire span of the tentorium rather than on a focal indentation along a segment of the transverse sinus. A broad-based mass effect of this nature would be expected to show itself where the "suspension bridge" configuration or hammock-like span of the tentorium is at its greatest. The secondary distortion of the anatomic structures (ie, dural leaves of the transverse sinus) at the insertion of the tentorial span would also be most prominent at this point of maximal span. This feature is consistent with the observed transverse sinus stenosis seen in patients with IIH, which is characterized by its location at the widest point of the tentorium in almost all patients, where surface tension of the dura would be predicted to be maximal. Simple generalized venous compression of the transverse sinuses does not appear to explain such a phenomenon, because venous compression/effacement of the dural sinuses elsewhere does not appear to be a variant expression of this pathologic epiphenomenon, at least not prominently.

Our observations raise intriguing questions as to the nature of the intracranial volumetric changes associated with IIH. Volumetric changes in CSF content of the intracranial cavity have been previously suggested as instrumental to the genesis of elevated ICP in this condition, ${ }^{12}$ but these results have been inconsistent. ${ }^{13}$ Oversecretion of CSF on the one hand or impaired absorption of $\mathrm{CSF}^{14}$ on the other do not seem to furnish satisfactory explanations for the observations made in IIH because oversecretion of CSF in cases of choroid plexus papilloma in the first instance or underabsorption of CSF following subarachnoid hemorrhage in the second do not give the same clinical or imaging appearance as IIH. ${ }^{15,16}$ Greater interest has focused on brain parenchymal changes, with hypothesized alterations in extracellular or intracellular fluid shifts in $\mathrm{IIH}^{17,18}$ and possibly more unexplored dynamic changes of the posited brain "glymphatic" system. ${ }^{19,20}$ Our results would seem to point to a supratentorial compartmental predilection for such changes, but this is not necessarily the only interpretation of these data. A supratentorial mass effect in $\mathrm{IIH}$, suggested by this study, could be simply a reflection of the greater magnitude of brain parenchymal volumetric change expressed in the supratentorial structures based on innate volume, compared with the intratentorial space.

Our study is limited on several counts. The characteristic effacement of the transverse sinuses, universally present in the patients with IIH group, prevented the use of a blinded process for measuring the geometry of the tentorium of interest in this study. The technique used is relatively simple and rudimentary and warrants confirmation with an automated technique if possible. A difficulty with consistent measurement of the landmarks of the transverse sinus between patients with IIH and controls is inevitable, with manual or automated techniques, by virtue of the necessity to measure a structure that is distorted and displaced by the disease process. The conformity of the tentorial curvature to the geometric circle construed in our measurements is variable and imperfect within both patient groups. However, the use of the geometric circle is conceptually illustrative, and variations of anatomic curvature away from a theoretic circle do not affect the core observations pertaining to the bowing of the tentorium. An additional potential limitation is that the controls were not matched for the subjects as to sex or body mass index.

The significance of our observations is 2 -fold. First, the hy- 
pothesis advanced in this article answers many of the questions previously posed as to the genesis of the transverse sinus effacement seen in patients with IIH and explains its characteristic location. A mechanical distortion of the transverse sinus by a deflection of the tentorium, rather than exclusively by venous compression of the transverse sinus by elevated ICP, makes more sense in view of many of the clinical observations made during transvenous manometry in patients with $\mathrm{IIH}$, such as incongruity between fluctuating ICP readings and elevated venous pressures. Elevated ICP alone does not seem to explain adequately the degree of venous effacement seen in many patients. Second, these results could suggest why some patients with IIH are more vulnerable to the development of secondary venous obstruction and hypertension if, for instance, the transverse sinus is innately narrowed by a pre-existing arachnoid granulation. Innate elasticity of the dura mater would also explain the reversibility of this venous stenotic phenomenon seen with effective medical or CSF diversionary procedures in IIH. ${ }^{21}$ Last, it behooves us to better understand the mechanical basis for venous stenoses in IIH, particularly if the transvenous stent treatment of this disorder continues its advance as a potential intervention for patients with medically refractory conditions. $^{22-28}$

\section{CONCLUSIONS}

Our data support the original hypothesis that a downward bowing or deflection of the tentorium cerebelli is detectable in patients with IIH compared with similarly aged controls. This observation points to a supratentorial mass effect of the disease or at least a preferential expression in that location. It also suggests that deformity of the tentorial insertion around the transverse sinus could be a fundamental mechanism for the genesis of venous stenotic changes that are well-recognized in this condition.

Disclosures: Pearse Morris—UNRELATED: Royalties: Lippincott, Williams \& Wilkins (textbook royalties).

\section{REFERENCES}

1. Friedman DI, Jacobson DM. Idiopathic intracranial hypertension. J Neuroophthalmol 2004;24:138-45 CrossRef Medline

2. Markey KA, Mollan SP, Jensen RH, et al. Understanding idiopathic intracranial hypertension: mechanisms, management, and future directions. Lancet Neurol 2016;15:78-91 CrossRef Medline

3. Friedman DI, Jacobson DM. Diagnostic criteria for idiopathic intracranial hypertension. Neurology 2002;59:1492-95 CrossRef Medline

4. Friedman DI, Liu GT, Digre KB. Revised diagnostic criteria for the pseudotumor cerebri syndrome in adults and children. Neurology 2013;81:1159-65 CrossRef Medline

5. Agid R, Farb RI, Willinsky RA, et al. Idiopathic intracranial hypertension: the validity of cross-sectional neuroimaging signs. Neuroradiology 2006;48:521-27 CrossRef Medline

6. Ridha MA, Saindane AM, Bruce BB, et al. MRI findings of elevated intracranial pressure in cerebral venous thrombosis versus idiopathic intracranial hypertension with transverse sinus stenosis. Neuroophthalmology 2013;37:1-6 CrossRef Medline

7. Maralani PJ, Hassanlou M, Torres C, et al. Accuracy of brain imaging in the diagnosis of idiopathic intracranial hypertension. Clin Radiol 2012;67:656-63 CrossRef Medline

8. Higgins JN, Gillard JH, Owler BK, et al. MR venography in idiopathic intracranial hypertension: unappreciated and misunderstood. J Neurol Neurosurg Psychiatry 2004;75:621-25 CrossRef Medline

9. Farb RI, Vanek I, Scott JN, et al. Idiopathic intracranial hypertension: the prevalence and morphology of sinovenous stenosis. Neurology 2003;60:1418-24 CrossRef Medline

10. Morris PP, Black DF, Port J, et al. Transverse sinus stenosis is the most sensitive MR imaging correlate of idiopathic intracranial hypertension. AJNR Am J Neuroradiol 2017;38:471-77 CrossRef Medline

11. Traboulsee A, Simon JH, Stone L, et al. Revised recommendations of the Consortium of MS Centers Task Force for a Standardized MRI Protocol and clinical guidelines for the diagnosis and follow-up of multiple sclerosis. AJNR Am J Neuroradiol 2016;37:394-401 CrossRef Medline

12. Donaldson JO. Cerebrospinal fluid hypersecretion in pseudotumor cerebri. Trans Am Neurol Assoc 1979;104:196-98 Medline

13. Malm J, Kristensen B, Markgren P, et al. CSF hydrodynamics in idiopathic intracranial hypertension: a long-term study. Neurology 1992;42:851-58 CrossRef Medline

14. Johnston I. Reduced C.S.F. absorption syndrome: reappraisal of benign intracranial hypertension and related conditions. Lancet 1973; 2:418-21 Medline

15. Eisenberg HM, McComb JG, Lorenzo AV. Cerebrospinal fluid overproduction and hydrocephalus associated with choroid plexus papilloma. J Neurosurg 1974;40:381-85 CrossRef Medline

16. Damkier HH, Brown PD, Praetorius J. Cerebrospinal fluid secretion by the choroid plexus. Physiol Rev 2013;93:1847-92 CrossRef Medline

17. Gideon P, Sørensen PS, Thomsen C, et al. Increased brain water self-diffusion in patients with idiopathic intracranial hypertension. AJNR Am J Neuroradiol 1995;16:381-87 Medline

18. Bastin ME, Sinha S, Farrall AJ, et al. Diffuse brain oedema in idiopathic intracranial hypertension: a quantitative magnetic resonance imaging study. J Neurol Neurosurg Psychiatry 2003;74:1693-96 CrossRef Medline

19. Iliff JJ, Nedergaard M. Is there a cerebral lymphatic system? Stroke 2013;44:S93-95 CrossRef Medline

20. Ueno M, Chiba Y, Murakami R, et al. Blood-brain barrier and bloodcerebrospinal fluid barrier in normal and pathological conditions. Brain Tumor Pathol 2016;33:89-96 CrossRef Medline

21. King JO, Mitchell PJ, Thomson KR, et al. Cerebral venography and manometry in idiopathic intracranial hypertension. Neurology 1995;45:2224-28 CrossRef Medline

22. Higgins JN, Owler BK, Cousins C, et al. Venous sinus stenting for refractory benign intracranial hypertension. Lancet 2002;359: 228-30 CrossRef Medline

23. Higgins JN, Pickard JD. Lateral sinus stenoses in idiopathic intracranial hypertension resolving after CSF diversion. Neurology 2004; 62:1907-08 CrossRef Medline

24. Higgins JN, Tipper G, Varley M, et al. Transverse sinus stenoses in benign intracranial hypertension demonstrated on CT venography. Br J Neurosurg 2005;19:137-40 CrossRef Medline

25. De Simone R, Ranieri A, Montella S, et al. The role of dural sinus stenosis in idiopathic intracranial hypertension pathogenesis: the self-limiting venous collapse feedback-loop model. Panminerva Med 2014;56:201-09 Medline

26. Elder BD, Goodwin CR, Kosztowski TA, et al. Venous sinus stenting is a valuable treatment for fulminant idiopathic intracranial hypertension. J Clin Neurosci 2015;22:685-89 CrossRef Medline

27. Satti SR, Leishangthem L, Chaudry MI. Meta-analysis of CSF diversion procedures and dural venous sinus stenting in the setting of medically refractory idiopathic intracranial hypertension. AJNR Am J Neuroradiol 2015;36:1899-904 CrossRef Medline

28. Starke RM, Wang T, Ding D, et al. Endovascular treatment of venous sinus stenosis in idiopathic intracranial hypertension: complications, neurological outcomes, and radiographic results. ScientificWorldJournal 2015;2015:14040 CrossRef Medline 